УДК 316

$10.17213 / 2075-2067-2021-3-32-38$

\title{
ПОЛИТИКО-АДМИНИСТРАТИВНЫЕ РЕСУРСЫ ИНСТИТУТА СИТИ-МЕНЕДЖМЕНТА
}

\author{
(C) 2021 г. А. Н. Зеленый
}

\section{Южно-Российский государственный политехнический университет (НПИ) имени М. И. Платова, г. Новочеркасск, Россия}

Цель работы. В данной работе предпринимается попытка оценить политико-административные ресурсы института сити-менеджмента.

Методология исследования. Проведен анализ эмпирических данных, полученных в результате экспертного опроса местных депутатов, заместителей глав администрации и представителей общественности.

Результаты исследования. По мнению автора, политико-административные ресурсы главы муниципального образования определяются порядком его легитимации, а также неформальными и теневыми нюансами процедур замещения этой должности. Отмечается, что исследователи оценивают потенциал сити-менеджмента только в формате идеальной модели и редко применяют соииологические эмпирические исследования, что не позволяет в должной степени оценить потенциал российского сити-менеджмента.

Использование результатов исследования. Итоги исследования указывают, что политико-административные ресурсы сити-менеджеров выме, чем у избранных мэров, но иеена их получения связана с утратой доверия местного сообщества.

Ключевые слова: сити-менеджмент; управленческий потенциал; муниципальное управление; институт сити-менеджмента; политико-административные ресурсы; вертикаль власти; муниципальная власть.

\section{POLITICAL-ADMINISTRATIVE RESOURCES OF THE INSTITUTION OF CITY-MANAGEMENT}

\section{(C) 2021 A. N. Zeleny}

\section{Platov South Russian State Polytechnic University (NPI), Novocherkassk, Russia}

The aim of the study. This paper attempts to assess the political-administrative resources of the institution of city-management.

Research methodology. The analysis of empirical data obtained as a result of expert survey of local deputies, deputy heads of administration and public representatives was carried out.

Research result. According to the author, the political and administrative resources of the head of a municipal entity are determined by the order of his legitimacy, as well as informal and shadow nuances of the procedures for filling this position. It is noted that the researchers assess the potential of city-management only in the format of an ideal model and rarely use sociological empirical studies, which does not allow to properly assess the potential of Russian city-management. 
Using of research results. The results of the study indicate that the political and administrative resources of city managers are higher than those of elected mayors, but the cost of obtaining them is associated with the loss of trust of the local community.

Key words: city-management; managerial potential; municipal government; institution of city-management; political-administrative resources; vertical of power; municipal power.

Введение. Основным отличием мэрской модели организации муниципальной власти от сити-менеджмента является порядок легитимации главы местной администрации, описанный в Ф3-131 «Об общих принципах организации местного самоуправления в Российской Федерации» [1]. Мэр и ситименеджер действуют в едином нормативном пространстве и обладают одинаковой целью - повысить качество жизни населения муниципальных пространств. На нормативном уровне не существует понятия «мэр» или «сити-менеджер», вместо них используется общий термин «глава муниципального образования», а институциональные нюансы приобретаются лишь за счет механизма легитимации этого статуса, обосновывающего разницу в политико-административных ресурсах [2]. Ресурсы мэра напрямую связаны с его политическим бэкграундом и социальными связями. Сити-менеджер, в отличие от мэра, ими не обладает, так как его появление в должности главы муниципального образования связано с решением конкурсной комиссии [3]. Эта комиссия формируется из 10 человек, половина из которых представлена губернатором, а вторая - председателем городской думы. Порядок формирования комиссии призван обеспечить паритет интересов акторов, действующих в одном институциональном пространстве, и сподвигнуть их к соглашению о «правилах игры». Однако социальная реальность может не соответствовать институциональным правилам и наполниться новыми нормами, носящими теневой и закрытый характер. Речь идет о возможности одного из акторов диктовать свою политическую волю другому и тем самым определять политико-управленческие ресурсы назначаемого на должность главы администрации сити-менеджера.

Исследователи муниципального управления критиковали мэрскую модель за то, что она допускает приход к власти популистов-непрофессионалов, имеющих значительный социально-политический капитал, но не обладающих административными компетенциями [4]. Сити-менеджер же является профессионалом и имеет необходимые знания для осуществления управленческой деятельности. Его компетентность и профессионализм - ресурс, проверяемый и оцениваемый конкурсной комиссией. Сама модель сити-менеджмента призвана не допускать попадания «во власть» людей, избранных из-за так называемой «избирательной стихии». Как следует из вышеописанного, сити-менеджер обладает отличными от мэра политико-административными ресурсами, определяемыми порядком его легитимации. Перед социологией управления стоит цель по выявлению потенциала сити-менеджеров в повышении качества жизни населения. Он определяется политико-административными и хозяйственно-экономическими ресурсами, которыми обладает нанятый по контракту управленец.

В этой работе мы сконцентрируем свое внимание на определении политико-административных ресурсов сити-менеджеров. Основной вопрос, ответ на который определяет оптимистичные и пессимистичные оценки перспектив российского сити-менеджмента, можно сформулировать следующим образом: содействуют ли имеющиеся у сити-менеджеров политико-административные ресурсы повышению показателей социально-экономического развития? Научное сообщество достаточно часто продуцирует множество умозрительных заключений, связанных с потенциалом сити-менеджмента, но не основывает свои аргументы на реальных процессах управления, имеющих место в реальной практике. В связи с этим мы предлагаем оценить эти ресурсы, опираясь на оценки самих субъектов муниципального управления. 
Методология исследования. В качестве респондентов по экспертному опросу были интервьюированы заместители глав администраций, депутаты представительного органа муниципальной власти, а также представители общественности - журналисты и преподаватели общественно-политических дисциплин в вузах. Исследование проводилось в Ростовской области, республиках Кабардино-Балкария, Адыгея и Крым. Общая выборка составляет 120 экспертов.

Результаты исследования. Первый вопрос касается понимания необходимости проведения муниципальной реформы.

Результаты таблицы 1 демонстрируют понимание необходимости повышения профессионализма муниципальных управленцев. Чуть меньше трети работников администрации не видят необходимости в новой форме организации муниципальной власти. Здесь четко вырисовываются группы сторонников и противников института сити-менеджмента. Наибольшее количество не одобряющих ситименеджмент экспертов принадлежит к группе общественников. Обращаем внимание на то, что заместители глав администраций смотрят на сити-менеджмент положительно и их понимание реформы совпадает с общими векторами развития властных отношений, ориентированных на вертикальное подчинение и управленческую эффективность.
Следующий вопрос имеет контрольный характер и направлен на выявление целей проводимой реформы по изменению легитимного порядка вступления в должность главы муниципального образования.

Сразу заметно, что наименьшее количество экспертов считает, что реформа была проведена из соображений продемонстрировать законотворческую имитационную активность. Второй по популярности опцией является повышение профессионализма муниципальных руководителей, которой придерживаются заместители администрации. Лидером мнений является позиция о выстраивании властной вертикали, что согласуется с общей тенденцией российской власти иерархизировать все отношения между организациями и институтами, контролировать их и распределять ресурсы согласно лояльности управленцев.

Для более детального выявления характеристик политических ресурсов в муниципальном управлении мы предложили экспертам несколько вариантов ответа, выбор которых кристаллизует понимание властной вертикали на муниципальном уровне.

Эксперты имели возможность выбрать несколько ответов. Среди представителей муниципальной власти наиболее популярной оказалась опция, связанная с возможностью отправить в отставку политически нелояльного сити-менеджера. Объяснить это можно

Таблица 1

Есть ли необходимость в повышении профессионализации муниципального управления с помощью создания института сити-менеджмента, в ед.

\begin{tabular}{|l|c|c|c|}
\hline \multicolumn{1}{|c|}{ Варианты ответов } & \multicolumn{2}{|c|}{ Социальный статус } \\
\cline { 2 - 4 } & $\begin{array}{c}\text { Заместители } \\
\text { глав } \\
\text { администраций }\end{array}$ & Депутаты & $\begin{array}{c}\text { Эксперты от } \\
\text { общественности }\end{array}$ \\
\hline $\begin{array}{l}\text { Нет, местное самоуправление в России ус- } \\
\text { пешно справляется со своими функциям }\end{array}$ & 12 & 4 & 5 \\
\hline $\begin{array}{l}\text { Нет, эффективность муниципального управ- } \\
\text { ления нужно повышать другими способами }\end{array}$ & 10 & 6 & 25 \\
\hline $\begin{array}{l}\text { Да, два десятилетия практики всенародного } \\
\text { избрания мэров показали неэффективность } \\
\text { данной модели }\end{array}$ & 14 & 1 & 4 \\
\hline $\begin{array}{l}\text { Да, сити-менеджмент предполагает только } \\
\text { одну оценку - профессионализм }\end{array}$ & 31 & 1 & 7 \\
\hline
\end{tabular}


распределительным характером отношений федеральной и муниципальной властей, где первая является донором ресурсов для второй. Очевидно, что в такой ситуации передавать какие-либо ресурсы нелояльным ситименеджерам просто не выгодно, следовательно, необходимо разработать механизм устранения от власти нелояльных глав местных администраций. Это также напрямую связано со вторым по популярности ответом достройкой властной вертикали. Если между муниципальной и федеральной властью выстроены распределительные отношения, где одна де факто зависит от другой, то обоснованным становится предположение о том, что власть хочет формализировать свое положение, навязав муниципалитетам модель ситименеджмента.

Итак, определившись с факторами, формирующими политико-административные ресурсы сити-менеджеров, перейдем к вопросам, непосредственно связанным с оценкой этих ресурсов.

В российской управленческой культуре человеку доверяют больше, чем институту, это обосновывает популярность третьей оп-

Таблица 2

Главная цель замены прямых выборов процедурой конкурсного отбора, в ед.

\begin{tabular}{|l|c|c|c|}
\hline \multicolumn{1}{|c|}{ Варианты ответов } & \multicolumn{3}{|c|}{ Социальный статус } \\
\cline { 2 - 4 } & $\begin{array}{c}\text { Заместители } \\
\text { глав } \\
\text { администраций }\end{array}$ & Депутаты & $\begin{array}{c}\text { Эксперты от } \\
\text { общественности }\end{array}$ \\
\hline $\begin{array}{l}\text { Экономическая (улучшить хозяйственное } \\
\text { развитие территорий) }\end{array}$ & 15 & 0 & 6 \\
\hline Политическая (достроить властную вертикаль) & 24 & 11 & 30 \\
\hline $\begin{array}{l}\text { Повысить профессионализм муниципаль- } \\
\text { ных руководителей }\end{array}$ & 21 & 1 & 5 \\
\hline $\begin{array}{l}\text { Никаких особых целей не было (реформа } \\
\text { ради реформы) }\end{array}$ & 7 & 0 & 0 \\
\hline
\end{tabular}

Таблица 3

Преследует ли замена прямых выборов мэра политические цели, в ед.

\begin{tabular}{|l|c|c|c|}
\hline \multirow{2}{*}{ Варианты ответов } & \multicolumn{3}{|c|}{ Социальный статус } \\
\cline { 2 - 4 } & $\begin{array}{c}\text { Заместители } \\
\text { глав } \\
\text { администраций }\end{array}$ & Депутаты & $\begin{array}{c}\text { Эксперты от } \\
\text { общественности }\end{array}$ \\
\hline $\begin{array}{l}\text { Достроить «властную вертикаль» для облегче- } \\
\text { ния возможности прямого администрирования }\end{array}$ & 30 & 8 & 24 \\
\hline $\begin{array}{l}\text { Упразднить на территориальном уровне все } \\
\text { политические отношения и связи, заменив } \\
\text { их административными }\end{array}$ & 3 & 2 & 20 \\
\hline $\begin{array}{l}\text { Исключить влияние партийного фактора на } \\
\text { процедуру избрания глав муниципальных } \\
\text { образований }\end{array}$ & 6 & 2 & 12 \\
\hline $\begin{array}{l}\text { Получить возможность отправить в отставку } \\
\text { политически нелояльного сити-менеджера }\end{array}$ & 31 & 4 & 8 \\
\hline $\begin{array}{l}\text { Никаких политических целей у института } \\
\text { сити-менеджмента нет }\end{array}$ & 24 & 0 & 4 \\
\hline
\end{tabular}


ции, связанной с тем, что принцип организации муниципальной власти не имеет значения, а важностью обладает лишь конкретный случай, связанный с конкретным человеком. Из этого следует, что политико-административные ресурсы сити-менеджера, по мнению экспертов, связаны не столько с порядком его легитимации, сколько с конкретными нюансами его назначения на должность. Мы предполагаем, что к власти может прийти по-настоящему эффективный хозяйственник и организатор, но также может прийти и «назначенец» от федеральной власти, основной целью которого будет поддержание статусакво. Каждое муниципальное пространство обладает своим уникальным характером, определяющим, какой сити-менеджер может быть назначен на должность главы администрации. Так, например, в крупных городах очень высока вероятность попадания

Таблица 4

Потенциал сити-менеджеров для хозяйственного развития в сравнении с мэрами, в ед.

\begin{tabular}{|l|c|c|c|}
\hline \multirow{2}{*}{\multicolumn{1}{|c|}{ Варианты ответов }} & \multicolumn{3}{|c|}{ Социальный статус } \\
\cline { 2 - 4 } & $\begin{array}{c}\text { Заместители } \\
\text { глав } \\
\text { администраций }\end{array}$ & Депутаты & $\begin{array}{c}\text { Эксперты от } \\
\text { общественности }\end{array}$ \\
\hline Да & 15 & 0 & 4 \\
\hline Нет & 10 & 5 & 13 \\
\hline $\begin{array}{l}\text { Принцип не имеет значения, все зависит от } \\
\text { каждого конкретного случая }\end{array}$ & 42 & 7 & 24 \\
\hline
\end{tabular}

Профессиональные преимущества сити-менеджеров по сравнению с публично избранными мэрами, в ед.

\begin{tabular}{|c|c|c|c|}
\hline \multirow[b]{2}{*}{ Варианты ответов } & \multicolumn{3}{|c|}{ Социальный статус } \\
\hline & $\begin{array}{c}\text { Заместители } \\
\text { главы } \\
\text { администрации }\end{array}$ & Депутаты & $\begin{array}{c}\text { Эксперты от } \\
\text { общественности }\end{array}$ \\
\hline $\begin{array}{l}\text { Сити-менеджер, в отличие от мэра, может за- } \\
\text { ниматься только хозяйственными функциями, } \\
\text { у него нет политической ангажированности }\end{array}$ & 15 & 0 & 12 \\
\hline $\begin{array}{l}\text { Неэффективного сити-менеджера можно до- } \\
\text { срочно отправить в отставку }\end{array}$ & 18 & 0 & 4 \\
\hline $\begin{array}{l}\text { Сити-менеджер не имеет политических обя- } \\
\text { зательств перед населением и поэтому спо- } \\
\text { собен принимать непопулярные, но необхо- } \\
\text { димые решения }\end{array}$ & 10 & 0 & 4 \\
\hline $\begin{array}{l}\text { Сити-менеджер - это управленец-профес- } \\
\text { сионал, избираемый профессионалами, в от- } \\
\text { личие от мэра, способного получить долж- } \\
\text { ность благодаря популистским приемам во } \\
\text { время выборов }\end{array}$ & 21 & 0 & 8 \\
\hline $\begin{array}{l}\text { У сити-менеджера нет никаких профессио- } \\
\text { нальных преимуществ перед мэром, избира- } \\
\text { емым муниципальным сообществом }\end{array}$ & 9 & 12 & 20 \\
\hline
\end{tabular}


на должность лояльного федеральной власти управленца, ориентированного на обеспечение порядка и стабильности, в то время как в малых городах сити-менеджер может продуктивно работать, не оглядываясь ни на что.

Перейдем к финальному вопросу, призванному напрямую спросить экспертов о преимуществах сити-менеджеров над мэрами.

Заключение. Из вышеприведенных данных можно вывести следующие тезисы. Заместители глав администраций как лица, непосредственно связанные с муниципальным управлением, основными преимуществами считают возможность уволить неэффективного сити-менеджера и видят потенциал в его профессиональных качествах. Эксперты от общественности смотрят на реформу скептически и считают, что изменение порядка вступления главы администрации в должность не принесет каких-либо преимуществ. Депутаты солидарны с общественниками и считают, что сити-менеджеры не обладают более серьезными преимуществами в сравнении с мэрами.

Подведем итоги экспертного опроса. Заместители глав администраций считают, что объем политико-административных ресурсов у сити-менеджеров выше, чем у мэров, они обладают более высокой квалификацией, имеют мотивацию, связанную с исполнением контрактных обязательств, свободны при реализации непопулярных решений. Вышеописанная позиция не совпадает с мнением депутатов и общественников, выражающих интересы потребителей муниципальных услуг, и предположительно связана с недоверием к местным органам власти вне зависимости от контекста обсуждения. Таким образом, реформа достигает своих целей, но в своеобразном и неоднозначном виде: приносит в жертву и так слабеющее доверие к муниципальной и федеральной власти, но, опираясь на принципы менеджеризма и приоритет управленческой эффективности над демократическими ценностями, повышает политико-административный ресурсный потенциал сити-менеджеров.

\section{Литература}

1. Федеральный закон от 06.10.2003 г. №131-Ф3 (ред. от 29.12.2020 г.) «Об общих принципах организации местного самоуправления в Российской Федерации».

2. Ковалев В.В., Чигрин В.А. Политикоадминистративные основания для модели «сити-менеджмента» в системе российского муниципального управления // Ученые записки Крымского федерального университета имени В.И. Вернадского. Социология. Педагогика. Психология. - 2018. - Т. 4. №2. - С. 30-38.

3. Самойлова А.С. Институциональные условия реализации модели сити-менеджмента в городском управлении // Вестник Томского гос. университета. Философия. Социология. Политология. - 2010. - №1 (9).

4. Ковалев В. В., Дятлов А. В. Состоятельность института сити-менеджмента (по материалам глубинных интервью с сити-менеджерами) // Гуманитарий Юга России. 2020. - T. 9 (46). — №6. - С. 111-118.

\section{References}

1. Federal'nyj zakon ot 06.10.2003 g. №131FZ (red. ot 29.12.2020 g.) «Ob obshhih principah organizacii mestnogo samoupravlenija $\mathrm{v}$ Rossijskoj Federacii» [Federal Law №131-FZ of 06.10 .2003 (as amended on 29.12.2020) «On the General principles of the Organization of Local Self-Government in the Russian Federation»)].

2. Kovalev V.V., Chigrin V.A. Politikoadministrativnye osnovanija dlja modeli «siti-menedzhmenta» V sisteme rossijskogo municipal'nogo upravlenija [Political and administrative bases for the model of «citymanagement» in the system of Russian municipal management] // Uchenye zapiski Krymskogo federal'nogo universiteta imeni V.I. Vernadskogo. Sociologija. Pedagogika. Psihologija [Scientific Notes of Vernadsky Crimean Federal University. Sociology. Pedagogy. Psychology]. - 2018. - Vol. 4. №2. - Pp. 30-38.

3. Samojlova A.S. Institucional'nye uslovija realizacii modeli siti-menedzhmenta $\mathrm{v}$ gorodskom upravlenii [Institutional conditions for the implementation of the model of city management in urban management] // Vestnik Tomskogo gos. universitetata. Filosofija. Sociologija. Politologija [Bulletin of Tomsk State University. Philosophy. Sociology. Political Science]. 2010. — №1 (9). 
4. Kovalev V. V., Djatlov A. V. Sostojatel'nost' instituta siti-menedzhmenta (po materialam glubinnyh interv'ju s siti-menedzherami) [Solvency of the Institute of City Management (based on the materials of in-depth interviews with city managers)] // Gumanitarij Juga Rossii. 2020. — Vol. 9 (46). — №6. — Pp. 111-118.

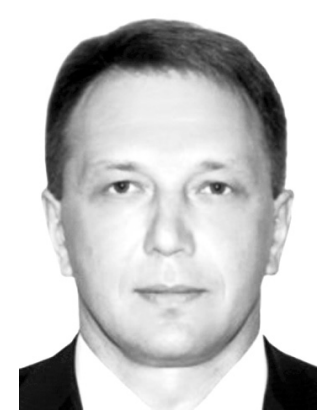

Зеленый Андрей Николаевич - аспирант Южно-Российского государственного политехнического университета (НПИ) имени М.И. Платова.

Zeleny Andrey Nickolaevich - Postgraduate student, Platov South Russian State Polytechnic University (NPI).

346428, г. Новочеркасск, ул. Просвещения, 132

132 Prosveshcheniya st., 346428, Novocherkassk, Russia

E-mail: green1969@mail.ru 